\title{
A FILMOGRAFIA COMO FACILITADORA DA DISCUSSÃO SOBRE TRABALHO INFANTIL NA AMAZÔNIA PARAENSE
}

Aline Cristina dos Santos Pereira

Discente do curso de Serviço Social. Bolsista do Projeto Infância em Tela na Universidade e na Comunidade. PIA/FASS/ICSA/UFPA. E-mail: acspereira12@gmail.com

Adrea Simone Canto Lopes

\begin{abstract}
Dra. em Desenvolvimento Rural - UFRGS; Mestre em Serviço Social; Pedagoga. Vinculada ao Programa Infância e Adolescência - PIA/FASS/ICSA/UFPA. E-mail: adreacanto@yahoo.com.br
\end{abstract}

\section{RESUMO}

Apresenta discussões acerca do trabalho infantil na Amazônia. Tem como objetivo apresentar as impressões de crianças e adolescentes acerca do trabalho infantil. Entendemos que a história da infância pobre no Brasil se construiu em meio ao trabalho e que o Estatuto da Criança e do Adolescente traz novas expectativas de mudanças nesse cenário. Assim, para debater sobre o assunto com as crianças e adolescentes, utilizamos a filmografia e observamos por meio de suas falas e desenhos que o trabalho ainda faz parte do cotidiano de crianças e adolescentes vinculadas ao projeto de extensão "Infância em Tela na Universidade e na Comunidade".

PALAVRAS-CHAVE: Infância. Adolescência. Trabalho. Filmografia.

\section{FILMOGRAPHY AS A FACILITATOR OF THE DISCUSSION ON CHILD LABOR IN THE PARAENSE AMAZON}

\begin{abstract}
It presents discussions about child labor in the Amazon. It aims to present the impressions of children and adolescents about child labor. We understand that the history of poor childhood in Brazil was built in the midst of work and that the Statute for Children and Adolescents brings new expectations for changes
\end{abstract}


in this scenario. Thus, to discuss the subject with children and adolescents, we used filmography and observed through their speeches and drawings that work is still part of the daily lives of children and adolescents linked to the extension project "Childhood on Screen at the University and at Community".

KEYWORDS: Childhood. Adolescence. Job. Filmography.

\section{INTRODUÇÃO}

A experiência relatada parte de uma atividade do Projeto de Extensão Infância em Tela na Universidade e na Comunidade que atua há 9 anos por meio do Programa Infância e Adolescência da Faculdade de Serviço Social, Instituto de Ciências Sociais Aplicadas da Universidade Federal do Pará.

O referido projeto, ancorado na experiência do Professor Giovanni Alves, idealizador do Projeto Tela Crítica na Universidade de Marília em São Paulo, tem como principal metodologia a utilização da filmografia como facilitadora na discussão de categorias infância, adolescência, família e políticas públicas, por meio do arcabouço teórico das Ciências Sociais Aplicadas, deste modo reporta-se a um debate de forma crítica e reflexiva.

Atualmente tem atuado em três instituições na região metropolitana de Belém além da própria universidade, sendo estes: Escola Estadual Mateus do Carmo, no bairro da Terra Firme; Instituição Social Lar Fabiano de Cristo, no bairro do Guamá e no Movimento República de EMAÚS, no bairro do Benguí. Até o mês de outubro de 2019 o projeto alcançou 390 pessoas entre discentes, técnicos, operadores do direito de crianças e adolescentes, pais e responsáveis, crianças, adolescentes e jovens.

A partir do que foi observado, compreende-se que o projeto tem possibilitado o processo de democratização do conhecimento acadêmico, de forma a estabelecer mecanismos de interação entre os saberes acadêmico e popular, de forma que a produção do conhecimento se efetive a partir do confronto com a realidade social. (NOGUEIRA, 2005)

Neste sentido, este trabalho discute a categoria trabalho infantil e infância no contexto da Amazônia paraense, possibilitada a partir de uma atividade do projeto de extensão Infância em Tela realizada na Escola Estadual de Ensino Fundamental Mateus do Carmo, localizada no bairro da Terra Firme, periferia de Belém, com crianças do $4^{\circ}$ ano do Ensino Fundamental na faixa etária entre 10 e 12 anos de idade do turno vespertino.

A atividade teve como objetivo discutir a categoria trabalho infantil, por meio do curtametragem 10 centavos, um drama de ficção dirigido por Cesar Fernando de Oliveira, com 
duração de 19 minutos produzido no estado da Bahia e narra sobre um garoto, que mora no subúrbio ferroviário de Salvador e se desdobra entre diversas atividades no centro histórico da cidade, como vigiar e/ou lavar carros, vender flores, para desta forma contribuir no sustento da família em troca de alguns trocados. Após a exibição do curta-metragem discutiu- se com os participantes as categorias citadas anteriormente.

\section{DESENVOLVIMENTO}

É importante ressaltar de antemão que neste trabalho compreende-se a infância como uma categoria histórica e social (ÀRIES, 1981; KRAMER, 1982). Segundo Kramer (1981) o conceito de infância não existiu sempre e da mesma maneira, ela aparece com a sociedade capitalista, urbano-industrial, na medida em que modificam a inserção e o papel social da criança na comunidade. Dessa forma se na sociedade Feudal, a criança exercia um papel produtivo direto ('de adulto') assim que ultrapassava o período de alta mortalidade, na sociedade burguesa ela passa a ser alguém que precisa ser cuidada, escolarizada e preparada para uma ação futura. E, na sociedade atual, a criança, assim como o adolescente são considerados sujeito de direitos, agentes sociais, que necessitam de cuidado, proteção, interação com meio social, e possuem diversos direitos ancorados em Convenções e legislações internacionais, como acesso à educação, à proteção, à vida digna etc.

Contudo, ainda com tantos direitos estabelecidos por meios legais, as crianças têm e vivem uma cultura social que lhes oferece outro tipo de infância, marcada pela luta de ser e estar no mundo a partir de sua realidade imediata, a qual envolve o trabalho, a falta de escola com qualidade, lazer e a ausência de efetivação de direitos.

Um dos condicionantes para a sujeição da criança ao trabalho infantil se dá pela desigualdade decorrente do contexto econômico, político e social. Segundo os dados da Fundação Abrinq, em 2018, estimava-se que no Brasil tinha-se 68,8 milhões de crianças e adolescentes entre zero e 19 anos de idade, e na região Norte apresenta a maior proporção de crianças e adolescentes, superando $41 \%$ da população em geral. Nesta região, 30,3\% da população de zero a 14 anos vive em situação domiciliar de pobreza e 33,9\% de extrema pobreza. Deste, $9,1 \%$ da população de crianças e adolescentes de cinco a 17 anos de idade estão ocupados (incluindo os ocupados na produção para o próprio consumo e/ou uso).

Compreende-se o trabalho como um conjunto de atividades realizadas, o esforço feito por indivíduos com objetivo de atingir uma meta. Além de ser um processo de transformação 
da natureza, que necessita de toda uma subjetividade e objetividade na qual as crianças ainda não estão preparadas. Desta forma, o trabalho na infância propicia consequências diversas para esta população, prejudicando o seu desenvolvimento físico, psicológico e intelectual, impedindo-as de desenvolver de maneira saudável todas as suas capacidades e habilidades.

Nesse sentido, foram estabelecidas diversas legislações que atuam para a erradicação do trabalho infantil. O artigo 60 do Estatuto da Criança e do Adolescente afirma que: "É proibido qualquer trabalho a menores de quatorze anos de idade, salvo na condição de aprendiz" (ECA, 1990).

O trabalho ${ }^{1}$, com diversas instruções é possibilitado na forma de aprendizagem conforme o artigo 62 do Estatuto que dispõe: "Considera-se aprendizagem a formação técnicoprofissional ministrada segundo as diretrizes e bases da legislação de educação em vigor" (ECA, 1990). Esta formação deve garantir o acesso e frequência obrigatória ao ensino regular; atividade compatível com o desenvolvimento do adolescente; além de que deve ser executada em horário especial para o exercício das atividades. Sendo assegurado ao adolescente bolsa de aprendizagem e ao adolescente aprendiz, maior de quatorze anos, são assegurados os direitos trabalhistas e previdenciários (ECA, 1990). Sendo vedado o trabalho perigoso, insalubre ou penoso; no período noturno, realizado entre as vinte e duas horas de um dia e as cinco horas do dia seguinte; ou realizado em locais prejudiciais à sua formação e ao seu desenvolvimento físico, psíquico, moral e social.

\section{RESULTADOS}

Ao debater estas questões com as crianças, foi possível obter diversos resultados, não somente por meio da oralidade, onde os participantes relataram de forma específica que: "as crianças só trabalham porque os pais não têm emprego." Flor ${ }^{2}, 10$ anos. Ou que: "as crianças trabalham porque tem vezes que são obrigadas.” Girassol, 11 anos. Ou ainda, relatando que: "meu irmão trabalha como aprendiz porque ele quer ter o dinheiro dele." Cravo, 10 anos.Ainda se levantou o debate acerca do excesso de atividades executadas em casa, como relatou uma das participantes: “Eu trabalho em casa. Eu acordo e tenho que fazer

\footnotetext{
${ }^{1}$ Entende-se por trabalho educativo a atividade laboral em que as exigências pedagógicas relativas ao desenvolvimento pessoal e social do educando prevalecem sobre o aspecto produtivo conforme é relatado no artigo $68, \S 1^{\circ}$ do Estatuto da Criança e do Adolescente.

${ }^{2}$ Neste trabalho, os nomes reais das crianças participantes foi substituído por nome de flores.
} 
varrer, lavar louça, cuidar da minha irmã..." Rosa, 11 anos. Contudo, foi possível observar as opiniões por meio dos desenhos elaborados por elas.

Como se pode observar nos desenhos abaixo:

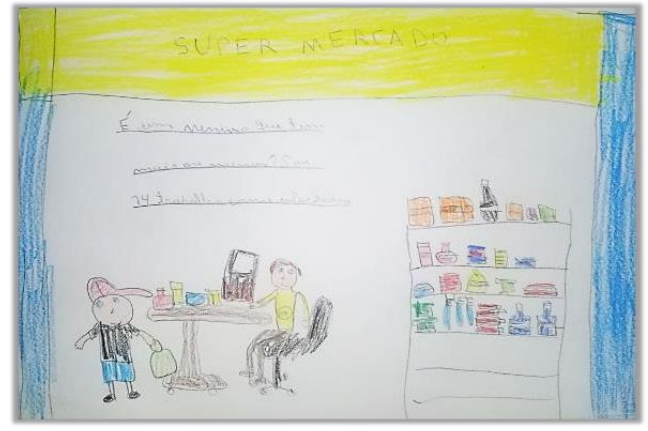

Figura 1: Menino trabalhando como empacotador em supermercado Fonte: Programa Infância e Adolescência / 2019

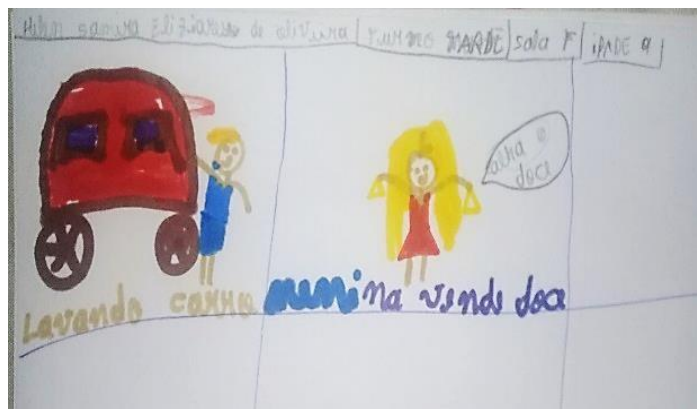

Figura 2: Menino lavando carro e menina lavando louça Fonte: Programa Infância e Adolescência / 2019

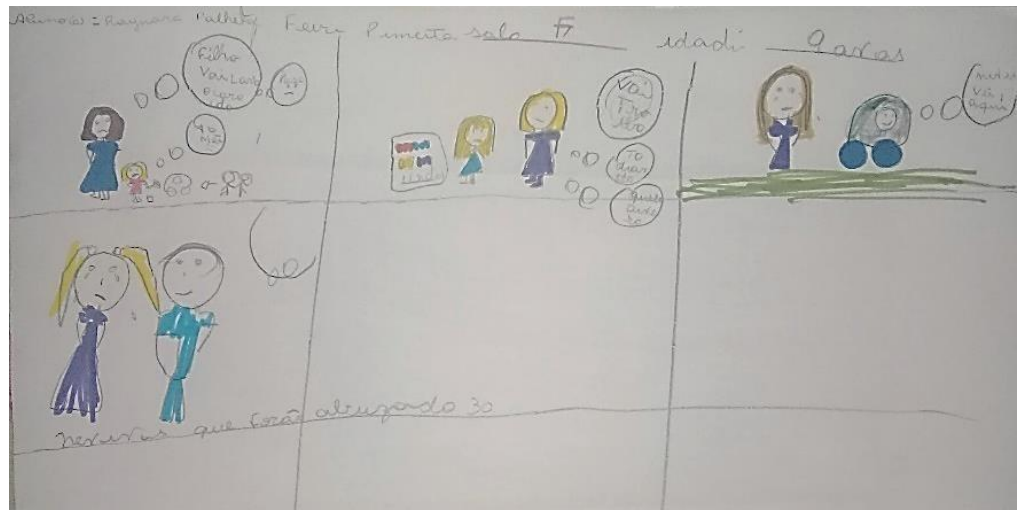

Figura 3: Menina vendendo laços na rua

Fonte: Programa Infância e Adolescência / 2019

Nos três desenhos expostos, podemos observar as crianças sendo representadas em diversos contextos de trabalho e vulnerabilidade. Na figura 1, observa-se um garoto trabalhando como empacotador em um supermercado. $\mathrm{O}$ autor do desenho, demonstra um adolescente, trabalhando na condição de aprendiz como empacotador. Neste contexto, inferese que o garoto retratado está protegido pelas legislações que o resguardam na estrutura do ensino aprendizagem, com provável acesso à escola conforme o ECA preconiza.

Na figura 2 e 3, pode-se observar a situação de três crianças em condição de trabalho infantil e vulnerabilidade social. Infere-se que os personagens estão na rua, expostos à violência, à acidentes e diversas outras formas de violações. $\mathrm{Na}$ imagem 3, em exceção, pode- se perceber a figura de uma mulher adulta nos primeiros quadros, onde se representa a 
mãe. Ao longo do diálogo estabelecido nos quadros 1 e 2, a mãe obriga a filha ao trabalho na rua, e posteriormente nos quadros 3 e 4 percebe-se um carro e a aproximação da figura de um homem, e no último quadro se percebe a criança demonstrando tristeza, através do desenho das lágrimas em seu rosto, e ao final a autora do desenho redigiu a seguinte frase: "Meninas que foram abusadas". Fazendo correlação ao trabalho infantil, à vulnerabilidade e à violência sexual contra crianças e prioritariamente meninas.

Desta forma, através desta atividade, conclui-se que o Projeto tem sido de suma importância para o fomento da informação acerca do direito das crianças e dos adolescentes, contribuindo para uma formação crítica e reflexiva da sociedade. Ressaltando, que através do desenho, das falas e da escuta sensível às crianças é possível uma interação lúdica, fecunda possibilitando o entendimento dos participantes.

\section{REFERÊNCIAS BIBLIOGRÁFICAS}

ARIÈS, Philippe. História social da criança e da família. Trad. Dora Flaksman. $2^{\mathrm{a}}$ edição. Rio de Janeiro: Zahar Editores, 1981. p. 279

FUNDAÇÃO ABRINQ. Cenário da Infância e Adolescência no Brasil. 2019.

KRAMER, Sônia. A política da préescola no Brasil: a arte do disfarce. Rio de Janeiro. Achiamé, 1982.

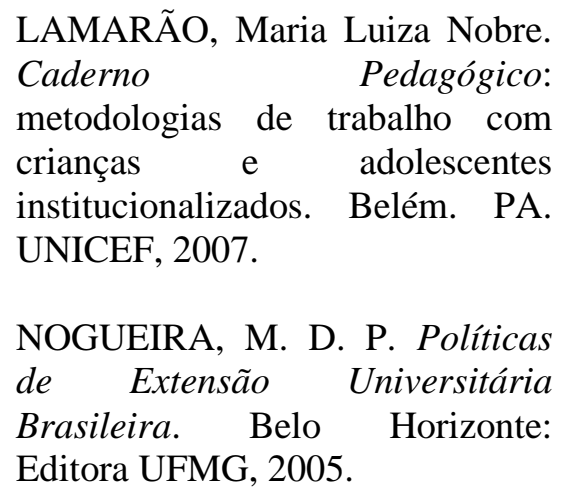

Editora UFMG, 2005.

PEREIRA. A.C.S., LOPES, A. S. C. A Filmografia Como Facilitadora da Discussão Sobre Trabalho Infantil na Amazônia Paraense. Complexitas - Rev. Fil. Tem. Belém, v. 4, n. 1, p. 3-8, jan./jun. 2019. Disponível em: http://www.periodicos.ufpa.br/index.php/complexitas/article/view/8045>. Acesso em: 30 de janeiro de 2020. 